\title{
Apartes del primer capítulo de la maravillosa obra de la historia de la Gineco-obstetricia en Colombia, escrita por el Dr. Fernando Sánchez Torres, la cual a nuestro juicio, debe convertirse en una obra ineludible de consulta de nuestras bibliotecas para ser leída desde los primeros años de formación profesional
}

\author{
Fernando Sánchez Torres*
}

\section{Panorama general}

La ginecobstetricia es la disciplina o actividad relacionada con los procesos normales y patológicos de los órganos reproductivos de la mujer. La primera referencia que se tiene acerca del ejercicio de esa actividad se encuentra, por supuesto, en los primeros documentos que se conocen, es decir, a partir de la época histórica. Aceptando que lo que ocurrió hacia atrás, en la época prehistórica, no es desconocido, cualquier versión sobre el acontecer ginecobstétrico de entonces sólo es producto de la imaginación o de la suposición. No obstante, como afirma Richard A. Leonard, no es fácil determinar exactamente dónde y cuándo acaba la medicina primitiva o imaginada, y dónde y cuándo empieza la moderna o documentada. Pero sí es fácil - añadimos nosotrosimaginar cómo transcurría el proceso fisiológico del embarazo y del parto en esa época primitiva, ya que no es descabellado extrapolar costumbres conocidas de tribus existentes en épocas modernas y que no han sido aún avasalladas ni influidas por la civilización. H. Buess, de Basilea, ofrece varios ejemplos en su ensảyo sobre la obstetricia primitiva.

Obstetricia etimológicamente significa "ponerse enfrente". Así lo registra J. Corominas. Pues bien, dado que el parto en aquellas épocas prehistóricas ocurría de manera solitaria, sin acompañamiento, ha de considerarse que esa fue, asimismo, la época preobstétrica. La mujer primitiva en trance de parto se alejaba de los suyos para aislarse y dar a luz sin nadie en frente, sola, en las orillas de los ríos o de las lagunas, o, según las circunstancias, en la soledad del bosque o en la oscuridad de la caverna, padeciendo los dolores sin gritar; como dice el citado Leonard, las fieras merodeaban muchas veces a su alrededor. La posición instintiva que adoptaba tenía que ser en cuclillas, pues así le era más fácil y productivo pujar. Ella sabía, igualmente de manera instintiva, como lo

Profesor Titular. Departamento de Obstetricia y Ginecología. Universidad Nacional de Colombia. saben las hembras de otras especies animales, que había que separar a su hijo de la placenta; lo hacía trozando el cordón umbilical por machacamiento o con el filo de una piedra. El agua, que era para muchas tribus una deidad o elemento purificador, se encargaba de limpiar la sangre de los genitales externos de la recién parida y del cuerpo del recién nacido.

Es probable que cuando el parto se hacía difícil, la parturienta suplicara ayuda; entonces alguna otra mujer acudiría a prestarla, en la forma más elemental: sirviéndole de acompañante, asistiéndola. Es de suponer también que en un momento dado alguna de esas asistentas abandonara su actitud pasiva y se atreviera a intervenir para ayudar de verdad, transformándose de esa manera en partera, personaje que iría a perdurar durante muchos siglos.

Los primeros documentos escritos que hasta nosotros han llegado son los papiros egipcios, que tienen una antigüedad cercana a los cuatro mil años. En el papiro de Ebers se consigna que la atención de los partos estaba a cargo de mujeres expertas. Igual cosa ocurría entre los hebreos, según relata la Tora. En la antigua Grecia, aquella anterior cuatro siglos a Jesucristo, cuando vivió Hipócrates, las mujeres ejercían la obstetricia y ocultamente la ginecología, que tenía ya verdadera personalidad médica. En la misma época igual ocurría en Roma. Para entonces Numa Pompilio decreta la práctica obligatoria de la operación cesárea postmortem.

Llegada la era cristiana, algunos médicos se muestran versados en dificultades obstétricas. Por ejemplo, Sorano de Efeso (98-138), introduce la versión podálica en momentos en que las mujeres dominaban el ejercicio ginecoobstétrico, autorizadas por el Estado. En efecto, existían las obstetrices o comadronas y las feminae medicae o ginecólogas. Las primeras atendían los partos sencillos, pero debían llamar a los médicos cuando surgían complicaciones; las segundas eran expertas en las enfermedades propias de la mujer.

Dice la historia que el primer comadrón o partero de verdad fue Pablo de Egina (652-690), que ejerció en 
Egipto y Asia menor y llegó a ser considerado como un oráculo en cuestiones atinentes a la reproducción humana. Este Pablo de Egina tuvo métodos originales: recomendaba que el parto en las mujeres obesas se atendiera acostándolas sobre su abdomen, las piernas levantadas hacia atrás. Puesto que Sorano de Efeso, que existió, como ya vimos, a principios del siglo segundo de nuestra era, se ocupó en uno de sus libros de la "silla obstétrica", podemos deducir que el parto se sucedía en aquellas calendas estando la mujer en posición sentada.

Por su parte, la ginecología hace su aparición en las páginas de la historia por la existencia del prolapso uterino y de los flujos o secreciones genitales. Así lo registra el papiro de Ebers. Fueron los hebreos quienes introdujeron el uso del espéculo para examinar vaginalmente a las mujeres que padecían de aquellos problemas. Tal aparato consistía en un cilindro móvil contenido en un tubo de plomo. En la Grecia antigua los médicos usaban sondas metálicas y dilatadoras de madera para explorar el útero.

El prolapso uterino era tratado mediante la "sucusión hipocrática", es decir, zarandeando a la mujer que se hallaba cabeza abajo, suspendida en lo alto por los pies. El espéculo vaginal para el examen, las fumigaciones y los pesarios medicamentosos ya eran también conocidos. Para evitar la maternidad no deseada, Sorano recomendaba que se taponara la boca del útero con una mecha de hilas.

El lapso transcurrido entre los siglos II y el XVI ha sido llamado "la oscura noche de la Edad Media", en razón de su improductividad en cuestiones médicas. Aún más, no sólo hubo estancamiento sino retroceso. En asuntos ginecobstétricos se volvió a la superchería y la magia, como en las épocas primitivas. Para confirmar lo anterior basta transcribir el relato que Demetrio Mereskowski dejó a la posteridad acerca del parto de la duquesa Beatriz Sforza, ocurrido en Milán en 1947, es decir, en los tiempos inmediatos al descubrimiento de América.

"La duquesa está de parto. Unos criados llevan un lecho largo y angosto provisto de un colchón duro, conservado desde tiempo inmemorial en el guarda-ropa del palacio, y en el que han tenido sus partos todas las duquesas de la casa Sforza. La parturienta tiene el rostro enrojecido y sudoroso, con mechones de cabellos pegados a la frente, $y$ de su boca abierta se escapa un continuo lamento. A su lado cuchichean las comadres, las criadas, las curanderas, las comadronas. Cada una tiene un remedio para la parturiente. Una vieja dama dice: "Sería necesario hacerle tragar una clara de huevo cruda, mezclada con seda purpúrea desflecada". Otra asegura que "lo que debía hacerse, era tomar siete gérmenes de huevos de gallina disueltos en una yema". Una propone envolver la pierna derecha de la parturienta en piel de serpiente. Otra atarle sobre el vientre la caperuza del marido. Otra hacerle beber alcohol filtrado por polvo de cuerno de ciervo y grana de cochinilla. Una vieja murmura: "La piedra de áquila bajo la axila derecha, la piedra de amante bajo la axila izquierda" y acercándose al duque con un gran plato de estaño, le dice: "Alteza, dignaos comer carne de lobo; cuando el marido come carne de lobo, la parturiente se siente mejor". El médico principal, acompañado de otros dos doctores, sale de la estancia, y dirigiéndose a un doctor joven, le indica en latín: "Tres onzas de limo de río, mezcladas con nuez moscada y coral rojo machacado". Alguien pregunta: “¿Acaso una sangría?" y contesta el viejo doctor: "Ya lo había pensado, pero desgraciadamente Marte está en el signo de Cáncer, en la cuarta esfera solar; y además está la influencia de una fecha impar". El doctor joven pregunta: “¿No creéis Maestro qué haría falta añadir a las limazas de río, estiércol de Marzo y bosta de vaca?". El duque va al encuentro de unos canónigos y de unos frailes que traen una parte de las reliquias de San Ambrosio, el cinturón de Santa Margarita, el diente de San Cristóbal, un cabello de la Virgen, etc." Termina el relato de esta manera: "Su alteza dio a luz un niño muerto y ella también murió el martes 2 de enero de 1497 a las 6 de la mañana".

\section{Algunas costumbres ginecobstétricas en el continente que sería hispanoamérica}

Las costumbres de los primitivos habitantes del mundo que descubrió Colón las conocemos a través de los cronistas de la conquista. Muchos de ellos fueron testigos de excepción, pues de manera directa se dieron cuenta de cómo vivían los naturales americanos; otros escribieron sus relatos alimentados por noticias que les suministraban descendientes directos de aquéllos; finalmente, la transmisión oral y la perpetuación de costumbres - la tradición- permitieron a algunos, siglos después, conjeturar acerca de lo que ocurría antes que se sintiera la influencia de la civilización extranjera.

Por supuesto que las cosas no eran iguales en toda la inmensa extensión territorial de la América India, pues los pueblos que la habitaban no tenían el grado de cultura. Hubo civilizaciones de verdadera avanzada para la época, como lo fueron la maya, la azteca y la incaica, y otras - la mayoría- verdaderamente primitivas. De ahí que se conozca mejor la historia de las primeras, en tanto que la de las otras se mantiene en la penumbra por sustracción de materia. Es explicable, entonces, que indagar por un aspecto específico de sus costumbres - como es el que nos interesa - constituya una labor frustrante, poco gratificante. Sin embargo, recordemos algunos hechos que se conocen.

\section{Los aztecas}

Refiere el cronista español Fray Bernardino de Sahagún que entre los aztecas el matrimonio ocurría a edad temprana, entre los 14 y los 16 años. La esterilidad femenina (tetzacotl) era mal vista y era causa de separación. Los asuntos que tenían que ver con la reproducción eran atendidos por mujeres conocidas como tlamatqui ticitl, o comadronas. El aborto provocado era permitido y estaba a cargo de éstas; a la mujer que abortaba se le llamaba cihuapectlin.

A la embarazada se le prodigaba una cuidadosa atención a manos de la ticitl, la cual disponía de ayudan- 
tas llamadas tepalehuiani. Dichos cuidados se acrecentaban en los últimos tres meses del embarazo. La gestante, particularmente la primigesta (ichpuchpihua), debía tomar baños de vapor (temazcalli), y se le daban consejos sobre ejercicios y alimentación. Al final del embarazo la comadrona practicaba una palpación abdominal y, si era el caso, ejecutaba la versión del feto mediante maniobras externas. La ticitl se trasladaba a la casa de la futura madre con antelación al parto para preparar ella misma los alimentos. Durante el trabajo de parto la mujer debía una poción de raíz de chihuapatli, que contiene eriocomina, una sustancia oxitócica. La posición habitual para la expulsión fetal era cuclillas. Sahagún afirma que las comadronas estaban capacitadas para ejecutar embriotomías en casos de feto muerto. Cuando había retención de placenta, practicaban la extracción manual.

Los aztecas consideraban como diosas (ciaopipiltin) a las que morían de parto; ellas iban al "Paraíso occidental" y cada mañana intervenían como parteras en el nacimiento del sol. Refiere Castelazo que "después del nacimiento, la partera lavaba al recién nacido, cortaba el cordón umbilical y le lavaba los ojos con cocimiento de xocopatli. Si el recién nacido era del sexo femenino, enterraba el cordón umbilical cerca del hogar, y si era varón era entregado a los guerreros que salían para que lo enterraran en el campo de batalla. El cronista Francisco J. Clavijero reseña con detalles el rito del nacimiento entre los aborígenes mexicanos. Dice así: "Cuando salía a luz el niño, la partera, después de haberle cortado el cordón umbilical y enterrado las secundinas, le lavaba el cuerpo, diciéndole estas palabras:"Recibe el agua, pues tu madre es la diosa Chalehiuhcueye. Este baño te lavará las manchas que sacaste del vientre de tu madre, te limpiará el corazón y te dará una vida buena y perfecta". Después, volviéndose a la diosa le pedía la misma gracia: tomando otra vez el agua con la mano derecha y soplando en ella, humedecía la boca, la cabeza y el pecho del niño. Seguía a esto un baño general, durante el cual decía la partera: "Descienda el dios invisible a esta agua y te borre todos los pecados y todas las inmundicias y te libre de la mala fortuna", y dirigiendo la palabra al niño, continuaba: "Niño gracioso, los dioses Ometeuctli y Omecihuatl te criaron en el lugar más alto del cielo para enviarte al mundo; pero ten presente que la vida que empiezas es triste, dolorosa, llena de males y de miserias; no podrás comer pan sin trabajar. Dios te ayude en las muchas adversidades que te aguardan"; y acababa la ceremonia dando la enhorabuena a los padres y parientes del recién nacido. Si éste era hijo de rey o de algún señor, visitaban a los padres sus principales súbditos para felicitarlos y vaticinar buena suerte al niño".

Es bueno añadir que los aztecas veneraban algunas deidades relacionadas con el proceso de la reproducción, así: Xochiquetzal, de la fertilidad; Cihuacoatl, de las parturientas primerizas; Xoloti, de los gemelos, de los fetos monstruosos y del aborto; Tlazolteotl, del parto y del amor; Metlacueyey, del puerperio. Igualmente, el ejercicio de la ginecología y la obstetricia no era patrimonio de las ticitl, pues existían hombres (Neconeticitl) que atendían parturientas y mujeres enfermas.

\section{Los mayas}

Las costumbres entre los mayas no difieren mucho de las que atrás hemos descrito de los aztecas, según lo relatado por Sahagún. Así lo confirma J. Augusto González, al describir lo ocurrido en el territorio de la actual Guatemala. La abogada o protectora de la maternidad era Ixchel, es decir, mujer arco iris; Ixquic, por su parte, era la diosa de la fecundidad. Como costumbre digna de mención conozcamos la forma como celebraban el nacimiento de los hijos: apenas nacida la criatura se sacrificaba un pavo. El baño se llevaba a cabo en algún río o fuente, donde hacían oblaciones de copal y sacrificio de papagayos. "El cordón umbilical se cortaba sobre una mazorca de maíz y con un cuchillo nuevo, el cual se arrojaba inmediatamente al río. Sembraban el grano de aquella mazorca y lo cuidaban con el mayor esmero, como cosa sagrada. La cosecha que de él provenía se dividía en tres partes, una para el adivino, otra para que sirviera de alimento al niño y guardaban la tercera para que éste la sembrase cuando estuviese en edad de hacerlo".

\section{Los incas}

Como se sabe, en la parte central de la América del Sur conocida con el nombre de Alto Perú floreció la cultura incaica, comparable a las culturas azteca y maya. Para los habitantes de esa región el aborto era severamente castigado según disposiciones del Inca Pachacutec. No obstante se llevaba a cabo mediante la administración de purgantes o masajes en el vientre. Francisco J. de Urioste, de quien hemos recogido estas noticias, señala que el infanticidio estaba autorizado si el recién nacido presentaba alguna deformidad. Durante el embarazo la mujer debía reducir su actividad laboral, ayunar con frecuencia y privarse de algunos alimentos, especialmente la sal. Se invocaba a Pacha Mama, es decir, la luna, para que el parto tuviera una feliz culminación.

Según J.M. Balcázar en su Historia de la medicina en Bolivia, el parto era asistido. Las mujeres daban a luz boca abajo, en cuatro pies, las manos en el suelo; la comadrona recibía la criatura por detrás. Empero, refiere el Inca Garcilaso de la Vega (citado por De Urioste) que las indias "parían sin partera, ni las hubo entre ellas; si alguna hacía oficio de partera, más era hechicera que partera". También cuenta Garcilaso que "llamaban Huaca a las cosas que salen de su curso natural, como a la mujer que pare dos de un vientre, a la madre y a los mellizos davan este nombre, por la extrañeza del parto, y nascimiento; a la parida sacavan por las calles con gran fiesta, y regocijo, y le ponían guirnaldas de flores, con grandes bailes y cantares, por su mucha fecundidad; otras nasciones lo tomavan en contrario, que lloravan teniendo por mal agüero tales partos".

Parece, no obstante el anterior testimonio de Garcilaso, que el parto, en efecto, era asistido. Una prueba fehaciente la aporta Lucas Molina Navia al referir la existencia de huacos (alfarería preincaica e incaica) que muestran a la parturienta sentada asistida por una mujer. También señala Molina que existen huacos - sin duda documentos de gran valor histórico-que ponen de presente que la 
operación cesárea era practicada en aquellas calendas. En el Alto Perú, según De Urioste, la parturienta se encerraba con la partera; al esposo le estaba prohibido ingresar a la habitación. La placenta y la sangre eran enterradas y cubiertas con arena. La madre descansaba en decúbito ventral durante ocho días. El Inca Garcilaso por su parte refiere que "la parida se regalava menos que regalava a su hijo porque pariendo, se iba a un arroyo o en casa se lavava con agua fría y lavava a su hijo y se volvía hacer las haciendas de su casa como si nunca hubiera parido".

Una costumbre curiosa es la que relata J.M. Balcázar refiriéndose al territorio boliviano: luego del parto el esposo se metía en la cama para despistar a los malignos. No hay duda de que lo que estilaban era la "covada" (del latín cubare: estar acostado), costumbre que se ha prestado para especulaciones de diferente tipo y que, según parece, ha sido observada en los distintos continentes y en todos los tiempos. Bernard This en su libro El padre: acto del nacimiento cita a Max Müller quien opina: "La couvade se dice aún, en ciertas hablas de Francia, de la caprichosa costumbre en virtud de la cual, cuando una mujer ha parido, el marido se mete en la cama, toma al niño y recibe las felicitaciones de sus vecinos. De los países vascos o de los Pirineos españoles, esta absurda costumbre parece haberse difundido hasta Francia, donde recibió el nombre de faire la couvade (hacer la covada)". Bastian, también citado por This, considera que esta costumbre tenía la finalidad de engañar a los diablos para que no hicieran daño a la mujer ni al recién nacido; al mismo tiempo permitía al padre afirmar su paternidad. Como vemos, la tal costumbre no fue traída por los conquistadores españoles ni tampoco trasladada por ellos a Europa. Según la escritora norteamericana Gena Corea - feminista infatigable y exaltada -, la covada no ha tenido otra finalidad que suplantar las funciones de la mujer; mediante esta costumbre, el decir suyo, "los hombres reniegan o devalúan la importancia de la mujer y pretenden parir ellos mismos". Claro que ella interpreta la "pollazón", que es la simulación de los dolores del parto por el hombre, como una forma extrema de la covada. Entre los araucanos, habitantes del extremo sur del continente americano, tenía vigencia la pollazóncovada, pues mientras la mujer paría, el marido guardaba cama y sólo se levantaba cuando aquella regresaba, es decir, a los ocho días posteriores al parto. Lo habitual era que permaneciera veinte días acostado, sin hablar, indiferente a todo, y su cuidado estaba a cargo de los vecinos, que le proporcionaban lo necesario para su subsistencia.

\section{Los araucanos}

Las aborígenes araucanas daban a luz en forma solitaria. Salían de su ruca o habitación y emigraban a sitios aislados, donde existiera agua (ríos o lagunas) y construían un pequeño rancho de ramas, que denominaban putracuma. Fuertemente asidas al poste central que sostenía al rancho, daban a luz en posición de cuclillas. Las yámanas, aborígenes de Tierra del Fuego, en posición de cuclillas. Las yámanas, aborígenes de Tierra del Fuego, se hacían auxiliar por las mujeres más ancianas de la localidad, o por sus propias madres. Estas ayudantas eran conocidas con el nombre de cutoandundomo, que quería decir "mujer que se compadece de la amiga". Después del parto, junto con su hijo, se daban un baño y se trasladaban a su morada donde permanecían ocho días. Al cabo de este tiempo se quemaban todos los utensilios que se hubieran usado, como también la choza donde había tenido lugar el parto. Es probable, según Manuel Avilés, que el parto fuera considerado como un acto impuro. E1 padre Diego Rosales, citado por el mismo Avilés, afirma que las madres solteras, por lo general, mataban a su hijo inmediatamente después del nacimiento, o si no lo dejaban abandonado. A éstos párvulos expósitos se les llamaba bucheñes. 